\title{
Functional Outcome Following Reverse Total Shoulder Replacement in the Setting of Trauma with Minimum 1 Year Follow-Up
}

\author{
Tony Farrell, Ciaran McDonald, John Lunn, Muiris Kennedy \\ Orthopaedic Department, Midlands Regional Hospital, Tullamore, Ireland \\ Email: Anthony.farrell@ucdconnect.ie
}

How to cite this paper: Farrell, T., McDonald, C., Lunn, J. and Kennedy, M. (2018) Functional Outcome Following Reverse Total Shoulder Replacement in the Setting of Trauma with Minimum 1 Year Follow-Up. Open Journal of Orthopedics, 8, 290-304.

https://doi.org/10.4236/ojo.2018.87032

Received: April 29, 2018

Accepted: July 13, 2018

Published: July 16, 2018

Copyright $\odot 2018$ by authors and Scientific Research Publishing Inc. This work is licensed under the Creative Commons Attribution International License (CC BY 4.0).

http://creativecommons.org/licenses/by/4.0/

(c) (i) Open Access

\begin{abstract}
Aims: To evaluate the short term functional outcomes following a reverse total shoulder replacement for complex neck of humerus fractures. Methods: A single centre retrospective case series evaluating all patients who underwent reverse shoulder arthroplasty following a complex neck of humerus fracture. Functional shoulder movements were assessed by two orthopaedic trainees at 1 year follow-up and compared to the opposite shoulder. Subjective assessment was measured using the Disabilities of the Arm, Shoulder and Hand (DASH) score and the Oxford Shoulder Score (OSS). Documentation of any complications was also noted. Findings: The reverse total shoulder replacement showed favourable outcomes both subjectively and objectively. Subjectively patients in this study scored a mean of $27.5+/-24.4$ (range $0-57.8$ ) in the DASH and $37.9+/-9.2$ (range $26-48$ ) in the OSS. There was a high negative linear correlation between the 2 scoring systems $(r=-0.95, p<0.05)$ indicating moderate to good shoulder function in most cases. The objective data also showed good functional outcomes with all patients having clinically similar function between the injured and uninjured limb. Conclusion: A reverse total shoulder replacement shows favourable subjective and objective outcomes for complex neck of humerus fractures in the trauma setting.
\end{abstract}

\section{Keywords}

Reverse Total Shoulder, Replacement, Trauma, Proximal Humerus, Fracture

\section{Introduction}

Humerus fracture is a common injury in the older person accounting for $4 \%$ $5 \%$ of all fractures [1]. In 2008, approximately $370,000 \mathrm{ED}$ visits in the US resulted from humerus fractures. This is expected to increase to 490,000 by the 
year 2030 following current trends [2]. Proximal humerus fractures were the most common, accounting for 50\% of all humerus fractures [1] [2].

The most common mechanism for fracture of the humerus is a fall directly onto the shoulder or arm with $87 \%$ of fractures resulting from a fall from ground level height [1] [3]. The proximal humerus is often fractured in patients with osteoporosis and is the third most common osteoporotic fracture type observed in elderly patients, after wrist and hip fractures [4]. This would largely explain why the incidence between females and males is 3:1 with an exponential increase in incidence as patients become older [2] [3] [4]. An expanding elderly population will inevitably increase the number of proximal humerus fractures and ED visits with subsequent referrals to orthopaedic services [2]. This case series aims to build the evidence for a reverse shoulder arthroplasty in the setting of trauma as a means of fixating complex proximal humerus fractures.

\subsection{Classification}

Proximal humerus fractures can be classified in different ways [5]-[10]. Arguably the most widely used is the Neer classification [5]. Neer divided the proximal humerus into 4 distinct parts: the greater tuberosity, the lesser tuberosity, the humeral head and the proximal shaft. They then classified fractures based on the displacement and angulation of these 4 parts (see Figure 1). According to the Neer classification, displacement of greater than one centimetre or angulation

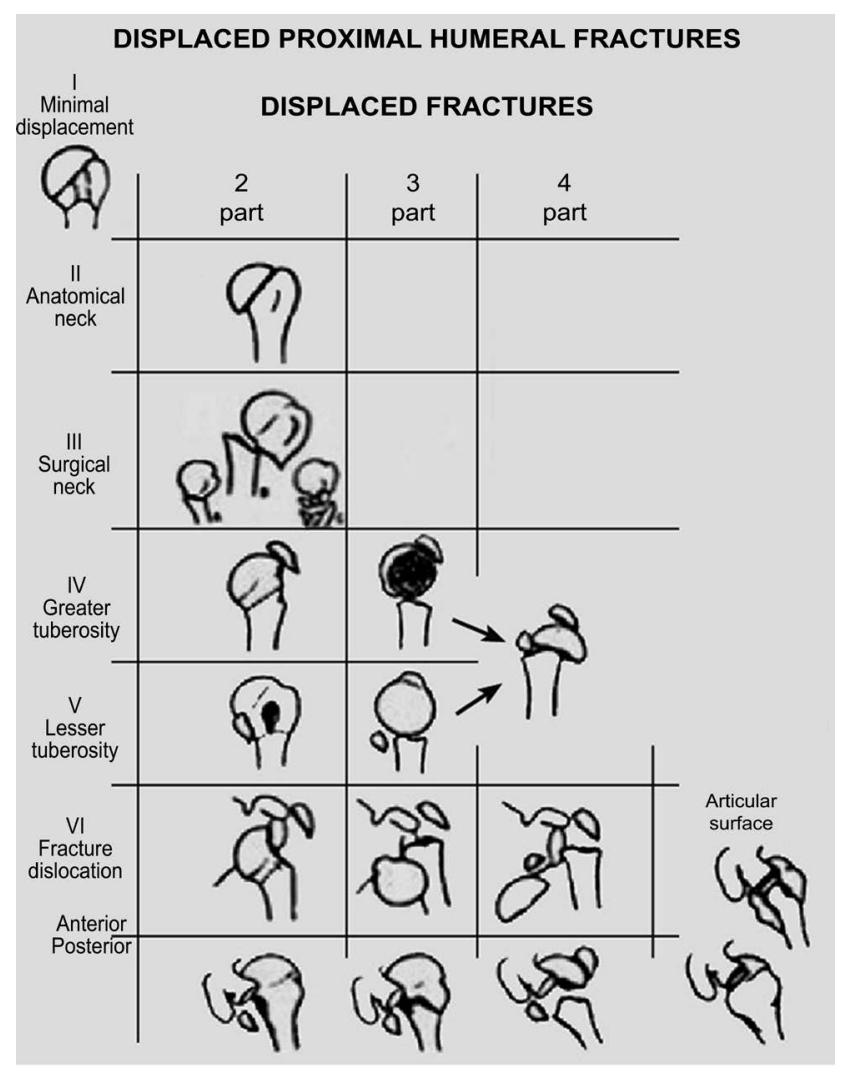

Figure 1. The Neer classification for proximal humerus fractures [5]. 
of more than $45^{\circ}$ is required for classification as a part [5] [6]. The significance of these 4 parts is each has a different deforming force meaning that reduction of 3 and 4 part fractures is challenging.

Hertel (2004) devised a similar classification and described 5 basic fracture planes with 12 distinct fracture patterns (see Figure 2). Hertel proposed that it was the fracture pattern rather than the amount of individual fragments that was most important. Hertel was interested in finding factors that could predict the likelihood of avascular necrosis of the humeral head. Factors they found to be important were; Length of metaphyseal head extension and Integrity of the medial hinge [7]. Importantly, they also correlated the fracture pattern with the incidence of humeral head ischemia with a positive predictive value of 0.7 [7] [8].

Although the Neer classification is widely used it is not correlated to humeral head ischemia. This is important because humeral head ischemia is a major contributing factor when deciding whether a proximal humerus fracture needs operative intervention with arthroplasty [11] [12] [13]. Ultimately, regardless of what scoring system one prefers, clinical judgment will be required when devising a management plan for a proximal humerus fracture. This case series hopes to provide information to both patients and clinicians when deciding if a reverse shoulder arthroplasty will be their best treatment option.

\subsection{Current Treatment Recommendations}

Up to $85 \%$ of Proximal humerus fractures are minimally displaced and can be treated conservatively [3] [14]. There is no consensus on what is the optimal treatment strategy for more complex fractures e.g 3 and 4 part Neer fractures or Hertel type 12 [5] [6] [7] [8]. Various techniques have been described for fixation of proximal humerus fractures. Some of which include; Intramedullary nailing [15], Tension band wiring [16], Closed reduction and pining [17] and open reduction with a various combinations of plates and screws [12] [13] [18].

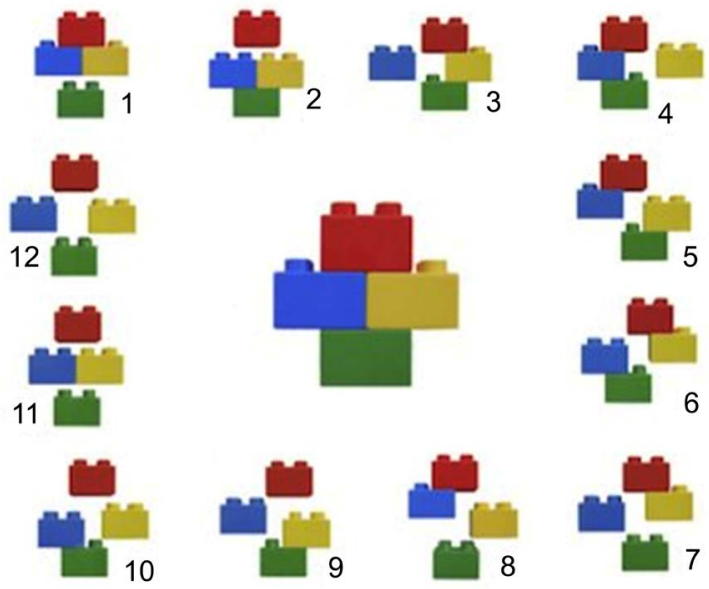

Figure 2. The Hertel Classification for proximal Humerus Fractures (Lego classification) [7]. Red $=$ Articular surface, Yellow $=$ Greater tuberosity, Blue $=$ Lesser Tuberosity, Green $=$ Shaft. 
Recommendations for most displaced two- and three-part fractures include internal fixation, with possible prosthetic replacement in three and four-part fractures that are not amenable to reconstruction [6] [11] [12] [13]. It has been well described that more complex fractures are more likely to disrupt the blood supply to the humeral head leading to AVN [7] [8]. Studies have suggested that AVN of the humerus head can be as high as $90 \%$ in some four-part proximal humerus fractures [6] [19]. Considering this data it is easy to see why a prosthetic shoulder replacement is an attractive treatment option for complex proximal humeral fractures.

To date there has been few randomised control trials looking at conservative management compared with arthroplasty for three and four part proximal humerus fractures [20]. The poorer outcomes associated with displaced, multipart fractures have resulted in surgical treatment options being explored. Neither the use of plates or replacement of the fractured humeral head (hemiarthroplasty) has been shown to be clearly superior to non operative fixation [21] [22] [23] [24]. Despite the trend of increased surgery for patients with displaced fractures of the proximal humerus the evidence available would seem to suggest that conservative management is as effective as some of the more traditional surgical treatments for 2 and some 3 part proximal humerus fractures [25].

Currently there is limited level 1 evidence regarding the optimal treatment of proximal humerus fractures with the most well know study being the PROFHER Trial [25]. As a result of this trial which looked at conservative versus surgical management of proximal humerus fractures in 250 patients there was a general move towards a more conservative approach for proximal humerus fractures [26]. However, it should be noted, that a reverse total shoulder replacement is only indicated in the most complicated of proximal humerus fractures. The PROPHER Trial included all patients with 2, 3 and 4 pat proximal humerus fractures [25]. Therefore although the general trend is now moving towards a more conservative approach the reverse total shoulder replacement is still considered a viable option for operative replacement.

Studies comparing reverse total shoulder replacement to hemiarthroplasty for the treatment of proximal humeral fractures have shown improved pain scores and functional outcomes [27] [28]. This would suggest that a reverse total shoulder replacement is a superior form of surgical treatment compared to the more traditional methods of treating these fractures such as hemiarthroplasty. If we consider that a hemiarthroplasty is not superior to conservative management for proximal humerus fractures in terms of outcomes and a reverse total shoulder replacement is superior to a hemiarthroplasty in terms of pain scores and functional outcomes then, it seems logical, that a reverse total shoulder replacement is superior to conservative management for complex proximal humerus fractures.

\subsection{Reverse Shoulder Arthroplasty}

The shoulder is a complex joint that relies on many opposing forces and ten- 
sions to provide a large range of motion [29]. As previously stated there are a number of deforming forces concentrated on a relatively small surface area [14].

The design of the reverse total shoulder arthroplasty medialises the center of rotation and brings the humerus to a more inferior position. This allows tension to be restored in the deltoid muscle belly and the functional lever arm which in turn improves the ability of the deltoid to move the humerus in space [29]. It has been reported that reversed total shoulder replacement provided excellent symptomatic relief and a pain free functional range of movement [30]. This is in stark contrast to some of the earlier studies on reverse total shoulder replacements which was reported to increase patient pain and reduce functional mobility [31]. New prosthetic design characteristics and surgical technique improvements are potentially factors that have dramatically improved patient outcomes.

Recent evidence would suggest that a reverse shoulder arthroplasty would be the preferred treatment method for surgeons in complex proximal humerus fractures [30]. However, to our knowledge, there is no single centre case series in Ireland that focuses on patient outcomes and quality of life following a reverse shoulder arthroplasty in the setting of trauma. Data from the United States suggests that we will see an exponential increase in proximal humerus fractures by the year 2030 and with this the increase in the demand for shoulder arthroplasties is inevitable [2]. This case series aims to build the evidence for a reverse shoulder arthroplasty as a treatment option in the setting of trauma for complex proximal humerus fractures.

\subsection{Functional Outcome Scoring Measures}

As previously stated a reverse total shoulder replacement is a superior form of surgical treatment compared to the more traditional methods of surgical replacement such as hemiarthroplasty in terms of pain and functional outcome [27] [28]. In order to assess these variables it is important to utilise numerous scoring systems so a general trend between patients can be observed. The ones choosen for this study focus on patient related outcome measures nameslyrhe DASH and the OSS.

\subsection{The Disabilities of Arm Shoulder \& Hand (DASH) Score}

The DASH outcome measure is a 30 -item, self-report questionnaire designed to measure physical function and symptoms in patients with musculoskeletal disorders of the upper limbs [32]. The DASH score is calculated by scoring patients on their ability to complete everyday tasks such as opening a jar or changing an overhead light bulb. The DASH score was shown to be reliable, valid, and responsive for patients with shoulder disabilities [33] [34] [35]. A higher DASH score (total 100 points) indicates a greater disability. Hunsaker (2002) [36] reported that the general population would score 10.1 on the DASH with a standard deviation of 14.68. This indicates that even in the uninjured shoulder the DASH accounts for reduced function that may be present from conditions such as osteoarthristis. 


\subsection{The Oxford Shoulder Score (OSS)}

The Oxford Shoulder Score is also a personal subjective assessment of shoulder pain and function assessing everyday activities such as ability to dress and pain in bed at night. The OSS has been described as a reliable, easy to use outcome measure which is sensitive to surgical outcome and clinical changes [37] [38]. In total it is scored out of 48 with a higher score indicating less pain and better shoulder function (see Table 1).

As the OSS and DASH are patient self-assessment measurement outcomes they could be expected to be interrelated to each other but may sometimes be used combined. Studies have reported that OSS is better to assess the surgical outcome in patients with rheumatoid arthritis as compared to the DASH [39] [40]. Neither has been shown to be superior to the other for trauma patients but both were used in this study as they focus on patient related outcomes measures and should have, in theory, a good correlation.

The aim of this retrospective case series is to evaluate the clinical outcome and the impact on quality of life of the reverse shoulder arthroplasty in the setting of trauma in a single centre case series in Ireland.

\section{Methods}

\subsection{Recruitment}

Extrapolation of theatre records to identify patients who have undergone a reverse total shoulder replacement in the setting of trauma between January 2014 and December 2017 in Tullamore Regional Hospital $(n=12) .2$ patients were not willing to participate. While 2 further patients were lost to follow-up. In total 8 patients were included in the case series.

\subsection{Participants}

There were 8 patients included in the case series; 1 male and 7 females (see Table 2). The average age of the participants was 73.3 years $+/-4.9$ years. The surgical site was evenly distributed between left and right. The indication for surgery was a comminuted 3 or 4 part proximal humeral head and neck fracture in all cases. All Fracture paterns were either a Neer classification 3 or 4 . There were

Table 1. Interpretation of the Oxford Shoulder score [38].

May indicate severe shoulder arthritis. It is highly likely that you may well require
some form of surgical intervention, contact your family physician for a consult with
an Orthopaedic Surgeon.
May indicate moderate to severe shoulder arthritis. See your family physician for an
assessment and x-ray. Consider a consult with an Orthopaedic Surgeon.
May indicate mild to moderate shoulder arthritis. Consider seeing you family
physician for an assessment and possible x-ray. You may benefit from non-surgical
treatment, such as exercise, weight loss, and /or anti-inflammatory medication
May indicate satisfactory joint function. May not require any formal treatment.


Table 2. Patient demographics.

\begin{tabular}{|c|c|c|c|c|c|c|c|}
\hline & Sex & Age & Side & $\begin{array}{l}\text { Time to } \\
\text { Surgery }\end{array}$ & Smoking Status & $\begin{array}{c}\text { Neer } \\
\text { Classification C }\end{array}$ & $\begin{array}{c}\text { Hertel } \\
\text { lassification }\end{array}$ \\
\hline Patient 1 & Female & 78 & Right & 3 days & no & 3 & 9 \\
\hline Patient 2 & Male & 64 & Right & 7 days & no & 3 & 7 \\
\hline Patient 3 & Female & 73 & Right & 21 days & $10 / 20$ per day & 4 & 12 \\
\hline Patient 4 & Female & 73 & Left & 6 days & no & 3 & 9 \\
\hline Patient 5 & Female & 80 & Left & 14 days & Ex $10 / 20$ per day & 4 & 12 \\
\hline Patient 6 & Female & 75 & Left & 3 days & no & 3 & 9 \\
\hline Patient 7 & Female & 70 & Right & 10 days & Ex $10 / 20$ per day & 4 & 12 \\
\hline Patient 8 & Female & 73 & Left & 5 days & no & 3 & 8 \\
\hline
\end{tabular}

three Hertel class 12's, three Hertel class 9's, one Hertel class 8 and one Hertel class 7 . The average time to surgery from time of the fracture was 8.6 days $+/-$ 6.2 days. There were 5 non smokers, 2 ex smokers and 1 current smoker in the study. The average time of data collection post op was 23 months +/- 10 months. The mechanism of injury was a fall from standing height in all cases.

\subsection{Surgeon and Equipment}

All procedures were performed by 2 consultant surgeons who specialise in upper limb injuries $(\mathrm{n}=2$ and $\mathrm{n}=6)$. The implants used were the Aequalis II Reversed Shoulder System ${ }^{\mathrm{TM}}$. The approach used was the delto-pectoral approach in all cases.

\subsection{Subjective Scores}

Participants were contacted by telephone and asked a series of questions relating to their quality of life. 2 separate scoring systems were used-The Disabilities of the Arm, Shoulder and Hand (DASH) Score and the Oxford Shoulder Score. These scores broadly categorised patients into good, average and poor function groups.

\subsection{Objective Scores}

All patients who participated in the study were invited into outpatient's clinic where flexion, extension, internal and external rotation of the affected limb were measured and compared with the uninjured limb. All measurements were ascertained by a consultant orthopaedic surgeon and 2 orthopaedic trainees using a standard goniometer. In total 6 measurements were taken of each limb.

\subsection{Recording Complications}

Patient records were reviewed and any intra operative and post operative complications were recorded.

\subsection{Radiological Review}

$\mathrm{X}$-rays taken at 1 day, 2 weeks and 3 months post operatively were reviewed in- 
dependently by 2 orthopaedic trainees and lorthopaedic consultant and any complications noted.

\subsection{Statistical Analysis}

All Statistical analysis was carried out using SPSS version 24. An Independent t-test was used to assess difference between groups for all shoulder movements. A linear regression analysis was used to determine the relationship between the DASH and OSS.

\section{Results}

\subsection{Quality of Life}

The average Disabilities of the Arm, Shoulder and Hand (DASH) Score was 27.5 +/- 24.4 while the average Oxford Shoulder score was $37.9+/-9.2$ see Table 3. There was a high negative linear correlation between the 2 scoring systems $r=$ -0.95 .

\subsection{Functional Movement}

Flexion, extension and abduction movements were similar in all patients between the injured and the uninjured limb with statistically significant differences noted in all movements (see Table 4 and Figure 3).

Flexion

There was a statistically significant difference between flexion of the injured $\operatorname{limb}\left(130.5^{\circ}+/-16.85^{\circ}\right)$ and the uninjured limb $\left(161^{\circ}+/-6.55^{\circ}\right) p<0.001$.

\section{Extension}

There was a statistically significant difference between extension of the injured $\operatorname{limb}\left(51.25^{\circ}+/-4.27^{\circ}\right)$ and the uninjured limb $\left(57.62^{\circ}+/-3.58^{\circ}\right) p=0.002$.

Abduction

There was a statistically significant difference between abduction of the injured $\operatorname{limb}\left(131.36^{\circ}+/-12.56^{\circ}\right)$ and the uninjured limb $\left(144.13^{\circ}+/-5.06^{\circ}\right) p=$ 0.004 .

Table 3. Comparative subjective quality of life data.

\begin{tabular}{ccccc}
\hline & Age & Months post op & DASH score & Oxford score \\
\hline Patient 1 & 78 & 12 & 7.8 & 46 \\
Patient 2 & 64 & 24 & 0 & 48 \\
Patient 3 & 73 & 28 & 56.9 & 26 \\
Patient 4 & 73 & 31 & 11.6 & 41 \\
Patient 5 & 80 & 25 & 50 & 27 \\
Patient 6 & 75 & 13 & 5.4 & 44 \\
Patient 7 & 70 & 37 & 57.8 & 28 \\
Patient 8 & 73 & 41 & 30.2 & 43 \\
\hline
\end{tabular}


Table 4. Comparative objective data for flexion, extension and abduction.

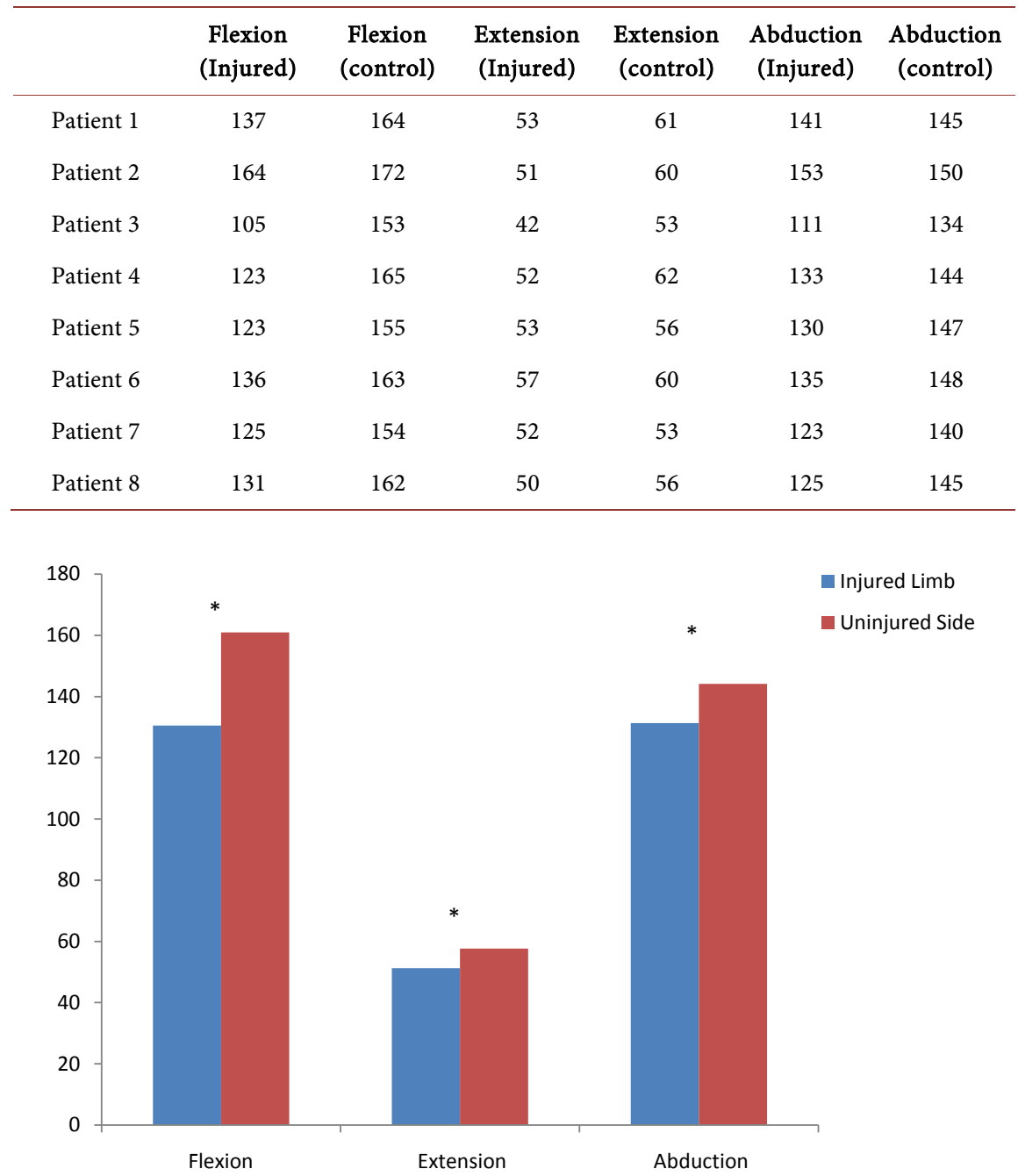

Figure 3. Objective data for flexion, extension and abduction. ${ }^{\star}$ There is a statistically significant difference $p<0.01$.

Adduction and external rotation were similar for all patients between the uninjured and the injured limb with no statistically significant difference observed between the 2 groups. There was a significant difference between the uninjured and injured side for internal rotation $(p<0.001)$ with the injured limb having a much less degree of movement compared to the uninjured side. Of note internal rotation is the only movement which showed clinically significant differences between the 2 groups. See Table 5 and Figure 4 .

\section{Adduction}

There was no statistically significant difference between adduction of the injured limb $\left(43.37^{\circ}+/-2.92^{\circ}\right)$ and the uninjured limb $\left(43.37^{\circ}+/-1.77^{\circ}\right) p=1$.

Internal Rotation

There was a statistically significant difference between internal rotation of the injured limb $\left(23.75^{\circ}+/-6.36^{\circ}\right)$ and the uninjured limb $\left(83.75^{\circ}+/-4.33^{\circ}\right) p<$ 0.001 . 
Table 5. Comparative objective data for adduction, internal rotation and external rotation.

\begin{tabular}{|c|c|c|c|c|c|c|}
\hline & $\begin{array}{l}\text { Adduction } \\
\text { (Injured) }^{\circ}\end{array}$ & $\begin{array}{l}\text { Adduction } \\
\text { (control) }^{\circ}\end{array}$ & $\begin{array}{c}\text { Int Rot } \\
\text { (Injured) }^{\circ}\end{array}$ & $\begin{array}{c}\text { Int Rot } \\
\text { (control) }\end{array}$ & $\begin{array}{c}\text { Ext Rot } \\
\text { (Injured) }^{\circ}\end{array}$ & $\begin{array}{c}\text { Ext Rot } \\
\text { (Control) }\end{array}$ \\
\hline Patient 1 & 46 & 45 & 21 & 85 & 34 & 46 \\
\hline Patient 2 & 48 & 45 & 34 & 90 & 47 & 46 \\
\hline Patient 3 & 44 & 42 & 13 & 84 & 44 & 42 \\
\hline Patient 4 & 41 & 43 & 30 & 82 & 42 & 43 \\
\hline Patient 5 & 40 & 40 & 23 & 75 & 42 & 40 \\
\hline Patient 6 & 45 & 43 & 22 & 84 & 36 & 42 \\
\hline Patient 7 & 40 & 44 & 21 & 87 & 48 & 41 \\
\hline Patient 8 & 43 & 45 & 26 & 83 & 41 & 45 \\
\hline
\end{tabular}

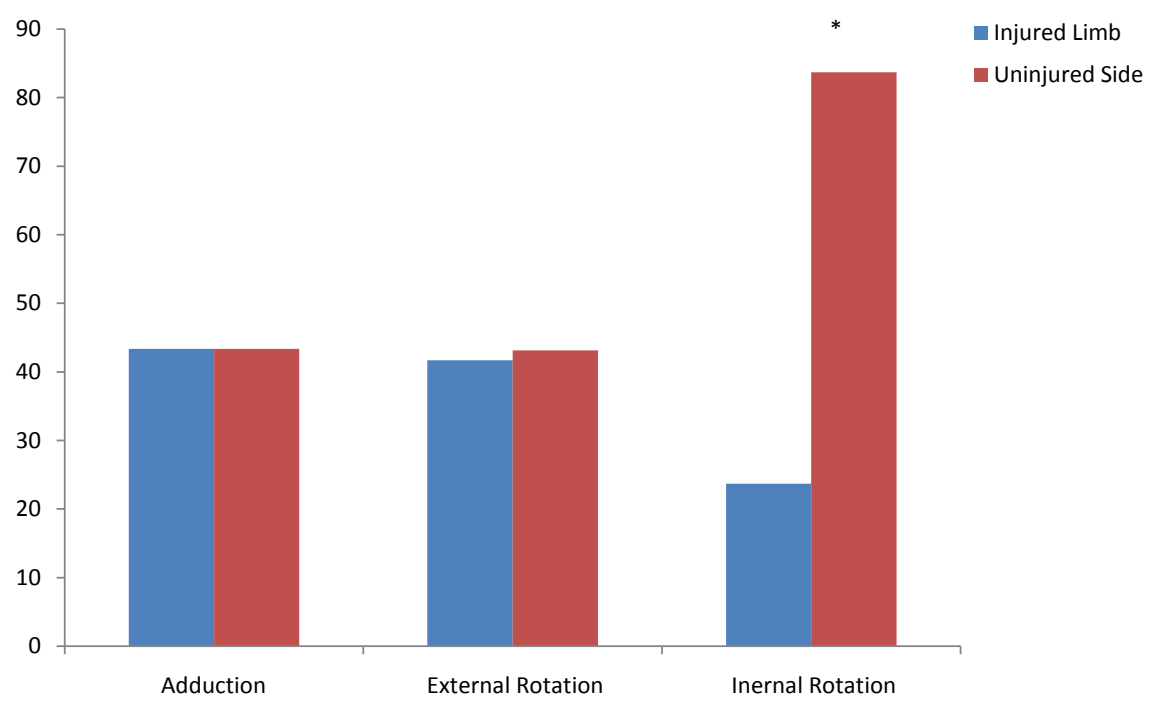

Figure 4. Comparative objective data for adduction, internal rotation and internal rotation. ${ }^{\star}$ There is a significantly significant difference $p<0.001$.

\section{External Rotation}

There was no statistically significant difference between external rotation of the injured $\operatorname{limb}\left(41.75^{\circ}+/-4.86^{\circ}\right)$ and the uninjured limb $\left(43.13^{\circ}+/-2.3^{\circ}\right) p=$ 0.528 .

\subsection{Complications}

There were no reported Intraoperative or post operative complications. Of note one patient experienced altered sensation along the distribution of the radial nerve that was present before their operation. This altered sensation originated from the time of their fall and had not fully resolved at 1 year follow-up.

\subsection{Radiological Review}

There were no radio-graphical complications recorded on plain films of the 
shoulder joints taken at 1 day, 2 weeks and 3 months post operatively.

\section{Discussion}

The optimal treatment of three and four part fractures of the proximal humerus has not yet been established. Operative treatment in the form of internal fixation or replacement such ashemiarthroplasty has not been shown to be superior over non-operative treatment. Early research has indicated that a reverse total shoulder replacement is superior to a hemiarthroplasty in terms of pain scores and functional outcome [27] [28]. This suggests that a reverse total shoulder replacement may be the treatment of choice in more complex proximal humerus fractures.

The results of this case series show that there is a statistically significant difference between the injured and uninjured limb for flexion, extension, abduction and internal rotation with the uninjured limb showing greater degrees of movement. It should be noted that only a clinical difference was noted for internal rotation with the uninjured limb having far greater degrees of movement compared to the injured side. This is to be expected as the design of the Aequalis II Reversed Shoulder System does not allow for internal rotation. Overall the objective differences noted does not seem to have affected the subjective perception of function as described by the DASH and the OSS.

The DASH score is calculated by scoring patients on their ability to complete everyday tasks such as opening a jar or changing an overhead light bulb. A higher DASH score (total 100 points) indicates a greater disability. Hunsaker (2002) reported that the general population would score 10.1 on the DASH with a standard deviation of 14.68. Patients in this study scored a mean of $27.5+/-$ 24.4 (range 0 - 57.8) indicating that in comparison to the general population those who underwent a reverse shoulder arthroplasty had a higher disability for everyday tasks.

The Oxford Shoulder Score is also a personal subjective assessment of shoulder pain and function assessing everyday activities such as ability to dress and pain in bed at night. In total it is scored out of 48 with a higher score indicating less pain and better shoulder function. The average Oxford Shoulder Score was $37.9+/-9.2$ (range 26 - 48).

There was a high negative linear correlation between the 2 scoring systems in this study $(\mathrm{r}=-0.95)$. This is to be expected as both scoring system focus on personal reporting of shoulder function with a high and low score being awarded to those with good function for the OSS and DASH respectively. Overall patients in this case series had reasonable shoulder function post op that was only marginally worse than what one would expect in the general population.

As this is only a small case series greater conclusions could be drawn with increased participant numbers and one of the limitations is that this case series focused on an elderly population so may not be applicable to all complex proximal humerus fractures. 


\section{Conclusions}

Humerus fractures are a common injury in the older person accounting for $4 \%$ $5 \%$ of all fractures. The research available would indicate that the incidence of proximal humerus fractures will increase exponentially in the next few years as the mean age of our population continues to increase. This will inevitably lead to increased referrals to orthopaedic services. As yet, the optimal treatment of three and four part fractures of the proximal humerus has not yet been established. The results of this case series indicates that a reverse total shoulder replacement provides positive objective and subjective patient related outcome measures. This is supported in the literature which showed that a reverse total shoulder replacement was superior to hemiarthroplasty for the treatment of proximal humeral fractures in terms of pain scores and functional outcomes.

Although more research is required before definitive conclusions can be drawn we conclude that a reverse total shoulder replacement is a viable option for definitive treatment of three and four part proximal humerus fractures in the setting of trauma.

\section{References}

[1] Chu, S.P., Kelsey, J.L., Keegan, T.H., Sternfeld, B., Prill, M., Quesenberry, C.P., et al. (2004) Risk Factors for Proximal Humerus Fracture. American Journal of Epidemiology, 160, 360-367. https://doi.org/10.1093/aje/kwh224

[2] Kim, S.H., Szabo, R.M. and Richard, M. (2012) Epidemiology of Humerus Fractures in the United States: Nationwide Emergency Department Sample, 2008. American College of Rheumatology, 64, 407-414.

[3] Horak, J. and Nilsson, B.E. (1975) Epidemiology of Fracture of the Upper End of the Humerus. Clinical Orthopaedics and Related Research, 112, 250-253. https://doi.org/10.1097/00003086-197510000-00032

[4] Launonen, A.P., Lepola, V., Saranko, A., Flinkkila, T., Laitinen, M. and Mattila, V.M. (2015) Epidemiology of Proximal Humerus Fractures. Archives of Osteoporosis, 10, 209. https://doi.org/10.1007/s11657-015-0209-4

[5] Neer, C. (1970) Displaced Proximal Humeral Fractures: Part I. Classification and Evaluation. The Journal of Bone \& Joint Surgery, 52, 1077-1089. https://doi.org/10.2106/00004623-197052060-00001

[6] McLaurin, M. (2004) Proximal Humerus Fractures in the Elderly-Are We Operating on Too Many? Hospital for Joint Diseases, 62.

[7] Hertel, R., Hempfing, A., Stiehler, M. and Leunig, M. (2004) Hertel's Binary or Lego Description System for Proximal Humerus Fractures. JSES, 13, 427-433.

[8] Hertel, R. (2005) Fractures of the Proximal Humerus in Osteoporotic Bone. Osteoporosis International, 16, 65-72.

[9] Boileau, et al. (2001) Sequelae of Surgery of Proximal Humerus Fractures: Boileau Classification. JSES, 10, 299-308.

[10] Kellam, J.F. and Audigé, L. (1988) Proximal Humerus Fracture: AO Classification. In: Müller, M., Eds., Manual of Internal Fixation, 118-125.

[11] Naranja, R.J. and Iannotti, J.P. (2000) Displaced Three- and Four-Part Proximal Humerus Fractures: Evaluation and Management. Journal of the American Acad- 
emy of Orthopaedic Surgeons, 8, 373-382.

https://doi.org/10.5435/00124635-200011000-00005

[12] Hintermann, B., Trouillier, H.H. and Schafer, D. (2000) Rigid Internal Fixation of Fractures of the Proximal Humerus in Older Patients. The Journal of Bone and Joint Surgery. British Volume, 82, 1107-1112. https://doi.org/10.1302/0301-620X.82B8.10330

[13] Hessmann, M., Gotzen, L., Gehling, H., et al. (1998) Operative Treatment of Displaced Proximal Humeral Fractures: Two-Year Results in 99 Cases. Acta Chirurgica Belgica, 98, 212-219.

[14] Court-Brown, C.M., Garg, A. and McQueen, M.M. (2001) The Epidemiology of Proximal Humeral Fractures. Acta Orthopaedica Scandinavica, 72, 365-371. https://doi.org/10.1080/000164701753542023

[15] Adedapo, A.O. and Ikpeme, J.O. (2001) The Results of Internal Fixation of Threeand Four-Part Proximal Humeral Fractures with the Polarus Nail. Injury, 32, 115-121. https://doi.org/10.1016/S0020-1383(00)00154-6

[16] Hawkins, R.J., Bell, R.H. and Gurr, K. (1986) The Three-Part Fracture of the Proximal Part of the Humerus: Operative Treatment. The Journal of Bone and Joint Surgery. American Volume, 68, 1410-1414. https://doi.org/10.2106/00004623-198668090-00014

[17] Jaberg, H., Warner, J.J. and Jakob, R.P. (1992) Percutaneous Stabilization of Unstable Fractures of the Humerus. The Journal of Bone and Joint Surgery. American Volume, 74, 508-515. https://doi.org/10.2106/00004623-199274040-00006

[18] Kristiansen, B. and Christensen, S.W. (1986) Plate Fixation of Proximal Humeral Fractures. Acta Orthopaedica Scandinavica, 57, 320-323. https://doi.org/10.3109/17453678608994401

[19] Jakob, R.P., Miniaci, A., Anson, P.S., et al. (1991) Four-Part Valgus Impacted Fractures of the Proximal Humerus. The Journal of Bone and Joint Surgery. British Volume, 73, 295-298. https://doi.org/10.1302/0301-620X.73B2.2005159

[20] Stableforth, P.G. (1984) Four Part Fractures of the Neck of Humerus. Journal of Bone and Joint Surgery, 66, 104-108. https://doi.org/10.1302/0301-620X.66B1.6693466

[21] Olerud, P., Ahrengart, L., Ponzer, S., Saving, J. and Tidermark, J. (2011) Internal Fixation versus Nonoperative Treatment of Displaced 3-Part Proximal Humeral Fractures in Elderly Patients: A Randomized Controlled Trial. Journal of Shoulder and Elbow Surgery, 20, 747-755. https://doi.org/10.1016/j.jse.2010.12.018

[22] Fjalestad, T., Hole, M.O., Hovden, I.A.H., Blucher, J. and Stromsoe, K. (2012) Surgical Treatment with an Angular Stable Plate for Complex Displaced Proximal $\mathrm{Hu}$ meral Fractures in Elderly Patients: A Randomized Controlled Trial. Journal of Orthopaedic Trauma, 26, 98-106. https://doi.org/10.1097/BOT.0b013e31821c2e15

[23] Boons, H.W., Goosen, J.H., van Grinsven, S., van Susante, J.L. and van Loon, C.J. (2012) Hemiarthroplasty for Humeral Four-Part Fractures for Patients 65 Years and Older: A Randomized Controlled Trial. Clinical Orthopaedics and Related Research, 470, 3483-3491. https://doi.org/10.1007/s11999-012-2531-0

[24] Olerud, P., Ahrengart, L., Ponzer, S., Saving, J. and Tidermark, J. (2011) Hemiarthroplasty versus Nonoperative Treatment of Displaced 4-Part Proximal Humeral Fractures in Elderly Patients: A Randomized Controlled Trial. Journal of Shoulder and Elbow Surgery, 20, 1025-1033. https://doi.org/10.1016/j.jse.2011.04.016

[25] Rangan, A., Handoll, H., Brealey, S., Jefferson, L., Keding, A., Corbachlo, B., Good- 
child, L., Hewitt, C. and Togerson, D. (2015) Surgical vs. Nonsurgical Treatment of Adults with Displaced Fractures of the Proximal Humerus. The PROFHER Randomised Clinical Trial. JAMA, 313, 1037-1047.

https://doi.org/10.1001/jama.2015.1629

[26] Jefferson, L., Brealey, S., Handoll, H., Keding, A., Kottam, L., Sbizzera, I. and Rangan, A. (2017) Impact of the PROFHER Trial Findings on Surgeons' Clinical Practice. Bone \& Joint Research, 6, 590-599.

[27] Cuff, D. (2012) Reverse Shoulder Arthroplasty for the Treatment of Rotator Cuff Deficiency. The Journal of Bone and Joint Surgery. American Volume, 94, 1996-2000. https://doi.org/10.2106/JBJS.K.01206

[28] Gallinet, D., Clappaz, P., Garbuio, P., Tropet, Y. and Obert, L. (2009) Three or Four Parts Complex Proximal Humerus Fractures: Hemiarthroplasty versus Reverse Prosthesis: A Comparative Study of 40 Cases. Orthopaedics \& Traumatology: Surgery \& Research, 95, 48-55. https://doi.org/10.1016/j.otsr.2008.09.002

[29] Lenarz, J. (2011) Christopher, Gobezie Reuben, Reverse Total Shoulder Arthroplasty. Journal of Visualized Experiments, 53, 2281.

[30] Kapur, R.A., McCann, P.A. and Sarangi, P.P. (2014) Reverse Geometry Shoulder Replacement Got Proximal Humeral Metastases. The Annals of the Royal College of Surgeons of England, 96, e32-e35. https://doi.org/10.1308/003588414X13946184903964

[31] Cazeneuve, J.F. and Cristofari, D.J. (2011) Long Term Functional Outcome Following Reverse Shoulder Arthroplasty in the Elderly. Orthopaedics \& Traumatology: Surgery \& Research, 97, 583-589. https://doi.org/10.1016/j.otsr.2011.03.025

[32] Hudak, P.L., Amadio, P.C. and Bombardier, C. (1996) Development of an Upper Extremity Outcome Measure: The DASH (Disabilities of the Arm, Shoulder and Hand) [Corrected]. The Upper Extremity Collaborative Group (UECG). American Journal of Industrial Medicine, 29, 602-608. https://doi.org/10.1002/(SICI)1097-0274(199606)29:6<602::AID-AJIM4>3.0.CO;2-L

[33] Gummesson, C., Atroshi, I. and Ekdahl, C. (2003) The Disabilities of the Arm, Shoulder and Hand (DASH) Outcome Questionnaire: Longitudinal Construct Validity and Measuring Self-Rated Health Change after Surgery. BMC Musculoskeletal Disorders, 4, 11. https://doi.org/10.1186/1471-2474-4-11

[34] Beaton, D.E., Katz, J.N., Fossel, A.H., Wright, J.G., Tarasuk, V. and Bombardier, C. (2001) Measuring the Whole or the Parts? Validity, Reliability, and Responsiveness of the Disabilities of the Arm, Shoulder and Hand Outcome Measure in Different Regions of the Upper Extremity. Journal of Hand Therapy, 14, 128-146. https://doi.org/10.1016/S0894-1130(01)80043-0

[35] Desai, A.S., Dramis, A. and Hearnden, A.J. (2010) Critical Appraisal of Subjective Outcome Measures Used in the Assessment of Shoulder Disability. The Annals of the Royal College of Surgeons of England, 92, 9-13. https://doi.org/10.1308/003588410X12518836440522

[36] Hunsaker, F.G., Cioffi, D.A., Amadio, P.C., Wright, J.G. and Caughlin, B. (2002) The American Academy of Orthopaedic Surgeons Outcomes Instruments: Normative Values from the General Population. The Journal of Bone and Joint Surgery. American Volume, 84, 208-215. https://doi.org/10.2106/00004623-200202000-00007

[37] Dawson, J., Hill, G., Fitzpatrick, R. and Carr, A. (2001) The Benefits of Using Patient-Based Methods of Assessment. Medium-Term Results of an Observational Study of Shoulder Surgery. The Journal of Bone and Joint Surgery. British Volume, 
83, 877-882. https://doi.org/10.1302/0301-620X.83B6.11316

[38] Olley, L.M. and Carr, A.J. (2008) The Use of a Patient-Based Questionnaire (the Oxford Shoulder Score) to Assess Outcome after Rotator Cuff Repair. The Annals of the Royal College of Surgeons of England, 90, 326-331.

https://doi.org/10.1308/003588408X285964

[39] Booker, S., Martin, S. and Gooding, B. (2015) Use of Scoring Systems for Assessing and Reporting the Outcome Results from Shoulder Surgery and Arthroplasty. World Journal of Orthopedics, 6, 244-251. https://doi.org/10.5312/wjo.v6.i2.244

[40] Dawson, J., Doll, H., Boller, I., Fitzpatrick, R., Little, C., Rees, J. and Carr, A. (2012) Specificity and Responsiveness of Patient-Reported and Clinician-Rated Outcome Measures in the Context of Elbow Surgery, Comparing Patients with and without Rheumatoid Arthritis. Orthopaedics \& Traumatology: Surgery \& Research, 98, 652-658. https://doi.org/10.1016/j.otsr.2012.05.011 